\title{
Assessment of Body Balance with the use of a Stabilometric Platform in Early Cerebral Infarction Sufferers
}

\section{Michalski Pawel ${ }^{1}$ and Kuszewski Michal ${ }^{2}$}

${ }^{1}$ Institute of Neurology, Specialistic Hospital, Czestochowa, Poland

${ }^{2}$ Department of Physiotherapy, Academy of Physical Education im. J. Kukuczki, Katowice, Poland

\section{Abstract}

Introduction: The post cerebral infarction condition results in significant functional degradation of the sufferer and reduces their quality of life. This work attempts to assess the balance in early cerebral infarction sufferers with the use of a stabilometric platform.

Material and methods: The examination covered a group of 30 patients with hemiparesis in 3 months from the cerebral infarction. Each patient was assessed by testing on the ALFA stabilometric platform. Results: A statistically significant difference was found in the examined group of patients between the healthy limb load (56\%) and the paretic limb load $(44 \%)(\mathrm{p}<0.001)$. A clearly defined negative relationship was found between the patient's age and stability $(\mathrm{p}<0.05 ; \mathrm{r}=-0.4)$, where stability is reduced when the age increases.

Conclusion: One of the effects of cerebral infarction is postural instability and difficulty in maintenance of erect position, where both are related to the disturbance of the body scheme. The analysis of the produced results for the loading difference between the healthy and plegic lower limb in sufferers with cerebral infarction has demonstrated that the load of the body increases on the healthy lower limb.

\section{Introduction}

Stability is the capacity for actively restoring the typical body posture in space lost due to destabilising factors. The ability to retain the vertical body posture and its stability control is based on a numerous group of reactions acquired during the phylogenetic development and achieved during the ontogenetic process of learning and memorizing the acts of movement. This forms the input for human locomotion activities and defines the mobility of a human being.

Locomotion is coordinated movement of specific body segments that use the interaction of internal and external forces. This mechanism allows maintaining the erect position and movement in space. The basis of locomotion is the action of the nervous, muscular and skeletal system [1].

The vertical body posture requires control, which depends on precise neuromuscular coordination. Here the most critical components include the central processing and coordination of visual information, vestibular system information output and deep sensory information output. A functional disturbance even in one of these centres will result in body posture stability disorders and loss of balance [2-4].

The most oppressive symptoms of apoplexy to its sufferers are the disturbance of limb mobility, usually in the form of paresis or paralysis, caused by the loss of the central regulation of muscular spindle irritability and the functional balance between the flexors and extensors. The severity and manifestation of apoplexy determine the capacity of maintaining body balance and proper gait.

The capacity to counter gravity is a necessary condition of every body movement. The CNS must anticipate, correct and secure each move. Hence balance disorders have the largest negative impact on the efficiency of rehabilitation from apoplexy. The balance reactions are caused with the help of positive and negative feedback mechanisms, which control motor behaviour within the CNS. Damage to the somatic system results in dissociation of the motor responses, especially those which monitor the muscular tension, which in turn gives disturbance in stability perception [5]. The loss of sensory and proprioceptive stimuli on the side opposite to the apoplectic focus removes the sensory stimulus primary component from the feedback, disrupts the spatial planning and assessment, which grade the muscular tone in programming, and this makes difficult to initiate postural adjustment. The limb movements on the healthy side of the body can be initiated and completed, but since the balance-restoring reactions and defence reflexes occur only on that side, the sufferer tips their body to the apoplectic side. This often results from additional muscular tone increase, or even from pushing oneself with the healthy leg in an attempt to restore balance.

The paresis of limbs (i.e. reduction of motor performance on the side opposite to the ischaemic focus) results in postural disorders, disturbed symmetry and disturbed body weight distribution, which turns into the disturbance of the gait pattern. Loss of dynamic balance may cause the patient to fall and suffer injuries, which are often the underlying cause for abandoning the rehabilitation [6,7].

Postural instability and difficulties in vertical posture retention in post stroke sufferers are related to the body schema disorder (i.e. hemispatial neglect)-and occur especially in damage of the non-dominant brain hemisphere-and spatial vision disorders (somatognosia); they are also related to the coordination of movements. Following a stroke, the patient may easily "forget" that the paretic body side exists; this is caused by the loss of dermal sensitivity or the sense of touch and the lack of sufficient signals for the brain. This leads to the loss of sense of stability [8].

The subject of this work was undertaken to evaluate by testing what the magnitude of balance disorders is as caused by hemiparesis in post *Corresponding Author: Kuszewski Michal, Department of Physiotherapy, Academy of Physical Education im. J. Kukuczki, Katowice, Poland; E-mail: kusza@wp.pl

Citation: Pawel M, Michal K (2015) Assessment of Body Balance with the use of a Stabilometric Platform in Early Cerebral Infarction Sufferers. Int J Phys Ther Rehab 1: 107. doi: http://dx.doi.org/10.15344/2455-7498/2015/107

Copyright: (C) 2015 Pawel et al.. This is an open-access article distributed under the terms of the Creative Commons Attribution License, which permits unrestricted use, distribution, and reproduction in any medium, provided the original author and source are credited. 
Citation: Pawel M, Michal K (2015) Assessment of Body Balance with the use of a Stabilometric Platform in Early Cerebral Infarction Sufferers. Int J Phys Ther Rehab 1: 107. doi: http://dx.doi.org/10.15344/2455-7498/2015/107

Page 2 of 4

stroke patients.

\section{Material and Methods}

The examination was carried out on 30 patients of both sexes undergoing treatment at the Neurological and Apoplectic Treatment Units and the Early Neurological Rehabilitation Unit of the St. Mary Provincial Specialised Care Hospital in Częstochowa, Poland (Polish: Wojewódzki Szpital Specjalistyczny im. Najświętszej Maryi Panny) The examined group included 15 males and 15 females aged from 25 to 78 years. 16 patients from the group ( 10 females and 6 males) had been diagnosed with left sided hemiparesis, whereas the remaining 14 patients ( 5 females and 9 males) had been diagnosed with right sided hemiparesis. The cerebral stroke had been diagnosed with historic data and neurological examination and proven by CT scans (Table 1).

Examination group criteria of inclusion:

- The post cerebral infarction condition must be proven by imaging

- The maximum time from infarction shall be 3 months

- The patient was fully fit prior to the infarction

- The first cerebral infarction is located in a brain hemisphere

- The patient must have a hemiparesis

- The logical contact must be sufficient to facilitate examination

- The patient shall be capable of assuming a vertical body posture and maintaining dynamic balance

Examination group criteria of exclusion:

- The time from infarction is over 3 months

- Restricted mobility of the lower limbs caused by pain, degenerative diseases, or various levels of LL amputation

- Inability to assume and maintain a vertical body posture for a min. of 1 minute

An ALFA stabilometric platform was used to examine the patients. The examination tests were carried out two hours after a meal, and the testing environment was a gym room. Each patient wore a loose, non-restrictive garment (a T-shirt and sweatpants).

\section{Alfa stabilometric platform}

Each patient stepped on the platform and assumed a position at which the centres of the lateral ankles were aligned with the red line on the platform deck. The patient's position was then read as follows:

- The position of the heels was read from two reference grids, each for the left and right foot on the deck (with the calcaneal tuber position input to the ALFA processing software);

- The angular alignment, being the angle between the inner extremity of the foot and the sagittal plane, was read on the scale located in the upper part of the platform.

Each patient stepped barefooted on the platform deck and assumed a relaxed vertical stance (with the legs straight in the knee joints and the arms loose down along the torso). Each patient gazed forward during the examination (without seeing the on-screen results). Each test would begin in 3 seconds from assuming a motionless vertical posture; the test start was preceded by a countdown displayed on a screen and began on a sound cue. The stabilometric platform deck features strain gauges which were used to record the translation of the centre of gravity projection (COP). The translation values were recorded in a computer system and displayed on a computer screen. Each test took 30 minutes to complete.
The stabilometric platform test results subject to subsequent analysis included these parameters:

- The load distribution between the paretic side leg and the healthy side leg;

- The COP deflection (path length), being the measure of stability.

\begin{tabular}{|l|l|l|l|l|l|}
\hline \multicolumn{5}{|l|}{ Statystyki opisowe } \\
\hline Zmienna & $\mathrm{n}$ & $\mathrm{x}$ & Min & Max & SD \\
\hline Age (year) & 30 & 56.87 & 25 & 78 & 11.37 \\
\hline Height $(\mathrm{cm})$ & 30 & 169.07 & 156 & 191 & 9.55 \\
\hline Weight $(\mathrm{kg})$ & 30 & 78.63 & 54 & 118 & 15.45 \\
\hline
\end{tabular}

\section{Results}

The Student's t-test analysis of the examination results for the load differential between the healthy LL and the paretic LL demonstrated a significantly higher load on the healthy LL $(\mathrm{p}<0.001)$. The healthy LL load amounted to $56 \%$, whereas the test subjects would load the paretic LL at $44 \%$. The results are shown in Figure 1.

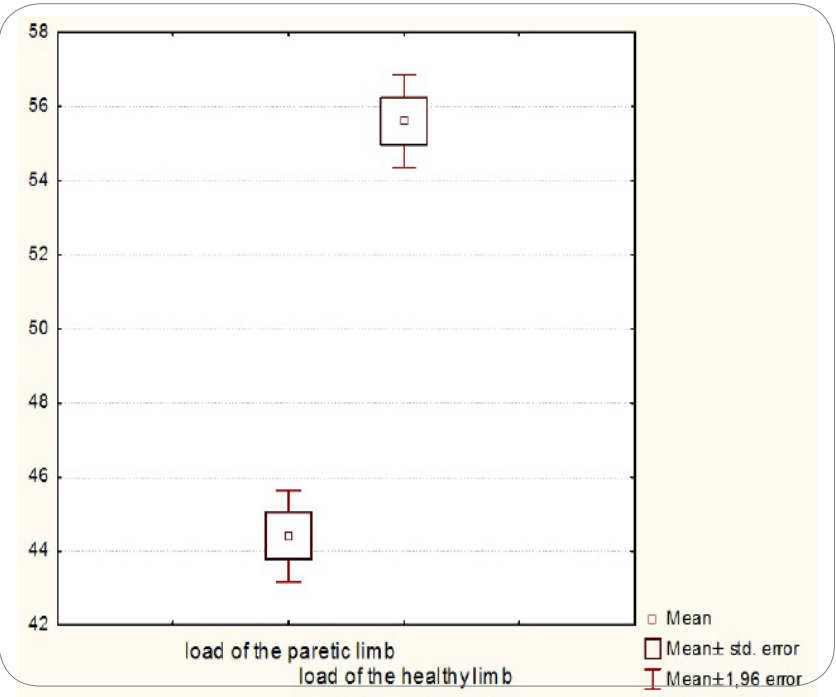

Figure 1: Analysis of the load differential between the healthy and paretic LLs.

Other parameters subject to analysis was the assessment of the relationship between the examinee's age and stability. The Pearson's linear correlation revealed a statistically significant negative relationship between age and COP deflection $(\mathrm{p}<0.05 ; \mathrm{r}=-0.4)$. The results are shown in Figure 2.

\section{Discussion}

Functional deficiencies caused by cerebral stroke are among the greatest challenges of modern rehabilitation. How challenging the rehabilitation of post-stroke sufferers can be is proven by the staggering number of clinical works and specialised methods and therapies in kinesitherapy and physiotherapy which stem from various therapeutic concepts [9-11]. A proper, early and thorough deployment of a rehabilitation regime increases short-term survivability, while improving the functional locomotor capacity of the body. This has been stressed by the American researchers under the Protocol for the Locomotor Experience Applied Post-Stroke (LEAPS) [12].

Numerous research works have enabled a deeper insight into the 


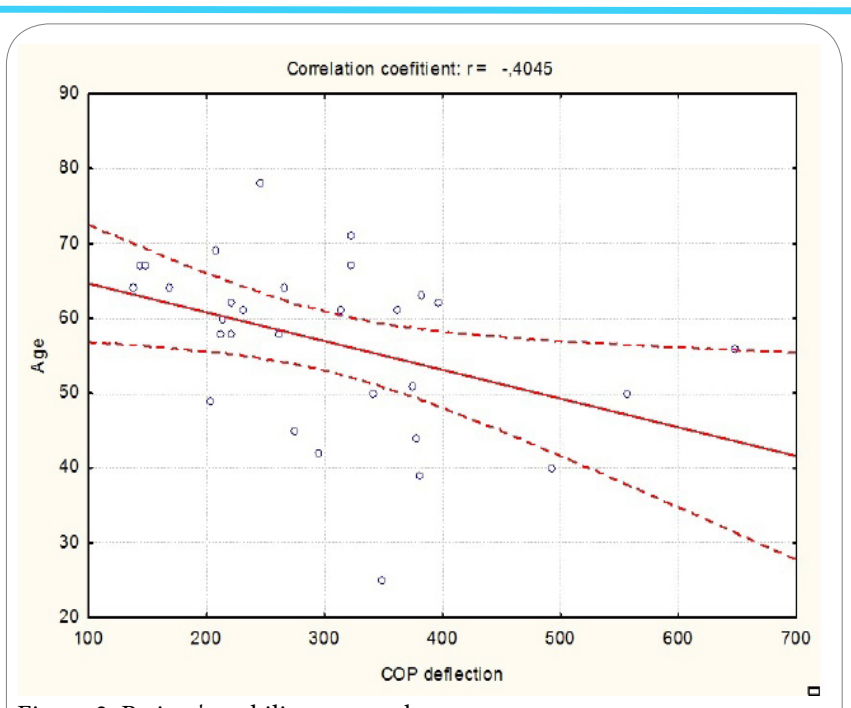

Figure 2: Patient's stability vs. age chart.

pathology of cerebral ischaemia and revealed that many neurons only manifest disorders of functions which can be saved by prompt deployment of special rehabilitative treatment (e.g. the Helsingborg Declaration or the Polish National Program for Cerebral Stroke Prevention and Treatment). The neural links and cortex "maps" are constantly reshaped by physical activity of the body. When complex movement activities are regularly undertaken, their area of cortex representation becomes larger.

Neural system disorders include the disturbance of voluntary action control, where integration of information is missing. This results in disturbance or absence of control over the body posture in space. In order to spatially balance the body, the centre of gravity is projected over a tetragonal support; an excessive deflection of the COP may result in swaying and, as a consequence, falling down. Balance retention is the ability to maintain the body COG (centre of gravity) over a defined support field [13].

As for the load relief asymmetry, De Haart et al. [14] have found that the COP deflection from the median is $10 \%$ in favour of the non-paretic LL. Other investigations into the load distribution have also proven that the paretic LL carries only approximately $40 \%$ of the body weight, which is consistent with the results shown herein. Lately the authors hereof have assessed the COP movements of each LL in separation, and the results of that work provide detailed information about the kinetic adjustment activities of each limb (i.e. the share of each limb in postural stability retention) [15-17]. Wan Assendolk et al. [15] determined that share of each LL from the torque (turning moment) of the tarsal joints in both legs. Their conclusion was that the paretic LL share in balance retention ranges from 11 to $45 \%$.

Research results [18-20] demonstrate an impairment of the feedforward balance control required for retaining the balance disturbed by the patient in cerebral stroke sufferers. An example of this is the often restriction of the ability to shift the body weight-especially on the paretic LL. De Haart et al. [21] investigated the capacity of voluntary body weight shifting in patients who rhythmically moved their body in a transverse direction at visual feedback cues of their COP. It took the patients more time to shift the body weight from the non-paretic $\mathrm{LL}$ to the paretic LL than in the opposite direction $(4.3 \mathrm{~s}$ and $3.5 \mathrm{~s}$, respectively). Healthy elderly persons would shift their body weight in both directions within the same time of $2.6 \mathrm{~s}$. Cerebral stroke sufferers were also found to display lower accuracy of body weight shifting than the healthy subjects. Other tests revealed that when a patient stood supporting the body weight on both LLs, they would maximally restrict the body weight shift in either direction, although shifting to the non-paretic LL was less impaired. The stroke sufferers could translate approx. $65 \%$ of the body weight on the paretic LL and 65 to $85 \%$ on the non-paretic LL, while healthy elderly subjects reached the body weight shift maximum of approx. $95 \%$ in both transverse directions [22].

The proprietary investigation into the patients revealed there is an asymmetry in the loading of lower limbs. The healthy side was loaded by ca. $10 \%$ more than the paretic side. The load distribution in healthy subject was identical on the left and right hand side.

Balance disorder testing is the most accurate with a stabilometric platform. However, the financial cost of that measuring instrument reduces the availability and universality of the test method. There are also a number of restrictions on proper performance of the test. The pareses, increased spastic tone, sensory disorders or contracture of periarthritic soft tissues which may be present in stroke sufferers make the required repeatability level a challenge [23]. Changes in the patient's balance retention ability are a major evaluation indicator in mobility therapies. The improvement in load relief of lower limbs favours the activation of paretic muscles and levels out the body weight distribution, which benefits the development of a correct gait pattern.

\section{Conclusion}

The analysis of the examination results for the load differential between the healthy LL and the paretic LL demonstrated a higher load on the healthy LL.

There is a clear negative relationship between age and stability. Stability is reduced with ageing.

\section{Competing Interests}

The authors have no competing interests with the work presented in this manuscript.

\section{Author Contributions}

Both the author substantially contributed to the study conception and design as well as the acquisition and interpretation of the data and drafting the manuscript.

\section{References}

1. Medved V (2001) Measurement of human locomotion. CRC Press LLC, 1.

2. Zajdel K, LataÅ,a B, Mosurska D (2009) [The usefulness of posturography and caloric tests in selected neurological diseases]. Przegl Lek 66: 920923.

3. Błaszczyk JW (2008) Sway ratio - a new measure for quantifying postural stability. Acta Neurobiol Exp (Wars) 68: 51-57.

4. Jodzio K, Gasecki D, Nyka W, Lass P (2004) [Cerebral blood flow in patients with various symptoms of hemispatial neglect following ischemic stroke]. Neurol Neurochir Pol 38: 381-388.

5. Ahlborg T, Berg S, Lindvig J (2013) Sense of coherence in first-time parents: a longitudinal study. Scand J Public Health 41: 623-629.

6. Wolny T, Saulicz E, Gnat R (2010) Ocena efektywnosci metody PNF w symetryzacji obciazenia konczyn dolnych u pacjentów w okresie póznym po udarze mózgu. Fizjoterapia Polska 10: 263-270

7. Srokowska A (2008) Ocena skutecznosci biologicznego sprzezenia zwrotnego w cwiczeniach na platformie MTD Control jako czynnika wspomagajacego fizjoterapie u osób po przebytym udarze mózgu. Balneologia Polska 2: 16-124. 
Citation: Pawel M, Michal K (2015) Assessment of Body Balance with the use of a Stabilometric Platform in Early Cerebral Infarction Sufferers. Int J Phys Ther Rehab 1: 107. doi: http://dx.doi.org/10.15344/2455-7498/2015/107

8. Mraz M, Curzytek M, Mraz MA, Gawron W, Czerwosz L, et al. (2007) Body balance in patients with systemic vertigo after rehabilitation exercise. Physiol Pharmacol 58 Suppl 5: 427-436.

9. Lang CE, Wagner JM, Edwards DF, Dromerick AW (2007) Upper extremity use in people with hemiparesis in the first few weeks after stroke. J Neurol Phys Ther 31: 56-63.

10. Kwakkel G, van Peppen R, Wagenaar RC, Wood Dauphinee S, Richards C, et al. (2004) Effects of augmented exercise therapy time after stroke: a meta-analysis. Stroke 35: 2529-2539.

11. Thommessen B, Wyller TB (2007) [Hospital-based rehabilitation after stroke]. Tidsskr Nor Laegeforen 127: 1224-1227.

12. Duncan PW, Sullivan KJ, Behrman AL, Azen SP, Wu SS, et al. (2007) Protocol for the Locomotor Experience Applied Post-stroke (LEAPS) trial: a randomized controlled trial. BMC Neurol 7: 39.

13. Krekora K., Czernicki J (2005) Ocena rozkladu sil nacisku na podloze u chorych po udarze niedokrwiennym mózgu. Rehabilitacja Medyczna 9: 1620.

14. de Haart M1, Geurts AC, Huidekoper SC, Fasotti L, van Limbeek J (2004) Recovery of standing balance in postacute stroke patients: a rehabilitation cohort study. Arch Phys Med Rehabil 85: 886-895.

15. van Asseldonk EH1, Buurke JH, Bloem BR, Renzenbrink GJ, Nene AV, et al. (2006) Disentangling the contribution of the paretic and non-paretic ankle to balance control in stroke patients. Exp Neurol 201: 441-451.

16. Laufer $Y$, Sivan D, Schwarzmann R, Sprecher E (2003) Standing balance and functional recovery of patients with right and left hemiparesis in the early stages of rehabilitation. Neurorehabil Neural Repair 17: 207-213.

17. Marigold DS, Eng JJ, Timothy Inglis J (2004) Modulation of ankle muscle postural reflexes in stroke: influence of weight-bearing load. Clin Neurophysiol 115: 2789-2797.

18. Januário F, Campos I, Amaral C (2010) Rehabilitation of postural stability in ataxic/hemiplegic patients after stroke. Disabil Rehabil 32: 1775-1779.

19. Said C, Galea M, Lythgo N (2013) People With Stroke Who Fail an Obstacle Crossing Task Have a Higher Incidence of Falls and Utilize Different Gait Patterns Compared With People Who Pass the Task. Phys Ther 93: 333345 .

20. Ryerson S, Byl NN, Brown DA, Wong RA, Hidler JM (2008) Altered Trunk Position Sense and Its Relation to Balance Functions in People PostStroke. J Neurol Phys Ther 32: 14-20.

21. de Haart M, Geurts AC, Dault MC, Nienhuis B, Duysens J (2005) Restoration of weight-shifting capacity in patients with postacute stroke: a rehabilitation cohort study. Arch Phys Med Rehabil 86: 755-762.

22. Eng JJ, Chu KS (2002) Reliability and comparison of weight-bearing ability during standing tasks for individuals with chronic stroke. Arch Phys Med Rehabil 83: 1138-1144.

23. Kostiukow A, Rostkowska E, Samborski W (2009) Assessment of postural balance function. Ann Acad Med Stetin 55: 102-109. 